\title{
A NEW TECHNIQUE TO SUPPLY FAST VARYING REACTIVE POWER USING A STATCOM
}

\author{
T. M. L. Assis \\ COPPE/UFRJ \\ P.O. Box 68504 \\ 21945-970 Rio de Janeiro, \\ Brazil \\ tatiana@nacad.ufrj.br_watanabe@coe.ufrj.br
}

\author{
L. A. S. Pilotto \\ Andrade \& Canellas \\ Alexandre Dumas, 2.100, $7^{\circ}$ andar \\ 04717-004 São Paulo, \\ Brazil \\ pilotto@andradecanellas.com.br
}

\author{
R. B. Sollero \\ CEPEL \\ P.O. Box 68007 \\ 21944-970 Rio de Janeiro, \\ Brazil \\ rbs@cepel.br
}

\begin{abstract}
This paper proposes a new technique to compensate fast oscillating reactive power using a multipulse STATCOM. It is shown that the oscillating reactive power can be controlled in a simple way by maintaining the STATCOM dc voltage constant. A simplified analytical analysis was performed in a power system with an arc furnace and a 12-pulse STATCOM. The study has shown that the STATCOM can compensate the furnace reactive current, even when fast oscillations occur. The system studied was implemented in a detailed EMTP/ATP simulation program. The results show that the reactive power oscillations produced by the furnace can be strongly reduced. However, due to the fact that arc furnace is an unbalanced load, STATCOM dc side capacitor has to be designed to supply the corresponding oscillating energy.
\end{abstract}

Keywords - Reactive Power Control, Shunt Compensation, STATCOM.

\section{INTRODUCTION}

To support dynamic disturbances such as transmission lines switching, loss of generation, short-circuits and load rejection, the reactive control must be fast enough to maintain the desired voltage levels and the system stability. These characteristics can be obtained using FACTS (Flexible ac Transmission Systems) controllers. Initially, equipment based on thyristors has been used (TCR - Thyristor Controlled Reactor, TSC - Thyristor Switched Capacitor and SVC - Static Var Compensator) and nowadays, equipment based on controlled switches such as GTO, IGBT and IGCT have already started to be applied. The Static Synchronous Compensator (STATCOM), which is based on voltage source converters (VSC), is one of the most used FACTS devices [1].

This paper presents a new technique to control fast oscillating reactive power using multi-pulse STATCOMs. The proposed technique is applied to control the oscillating reactive power produced by an arc furnace.

\section{REACTIVE POWER IN STATCOM}

The STATCOM is a key FACTS shunt compensator. There are many types of STATCOMs, depending basically on the control philosophy and application objectives. Here, a multi-pulse STATCOM, based on 6-pulse converters, will be used for voltage control. Each 6-pulse converter switches at

Manuscript received on May 30, 2005; revised on August 3rd, 2005. Recommended by the Editor José Antenor Pomilio. fundamental frequency which presents losses during steadystate operation less than the losses presented by the PWMSTATCOM [1]. In its dc side, the STATCOM has a capacitor and is connected to the ac system through one or more transformers, depending on the number of pulses $(6,12,24$ or 48 pulses).

The reactive power in the STATCOM output is controlled through the dc capacitor voltage. In steady-state operation, there is no angular difference between the voltage at the STATCOM ac side and the system voltage (ideal case). This way, the reactive power in the STATCOM output can be approximately calculated through (1), according Figure 1.

$$
Q_{S T}=\frac{V_{S T}}{X_{S T}}\left(V_{S T}-V_{P C C}\right),
$$

where:

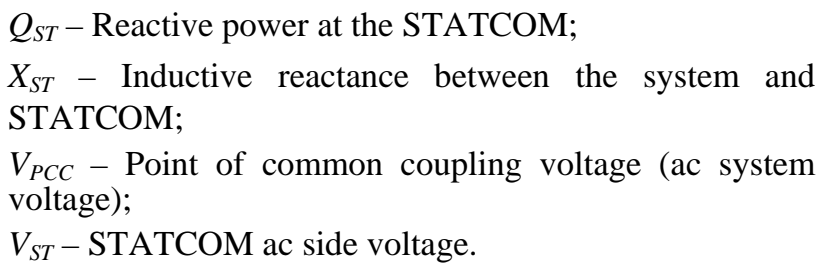

As it is well known [1], (1) shows that if the STATCOM ac side voltage is higher than the system voltage $\left(V_{P C C}\right)$, its reactive power has capacitive characteristic. On the other hand, if the system voltage is higher than $V_{S T}$, the STATCOM reactive power has inductive characteristic.

\section{THE PROPOSED CONTROL TECHNIQUE}

The reactive power variation is the primary contributor for voltage variations in all points of a power system.

Equation (1) shows that the difference between STATCOM ac side voltage and the system voltage defines the reactive power characteristic. Moreover, the higher this difference is, more reactive power will be supplied by the STATCOM, capacitive or inductive.

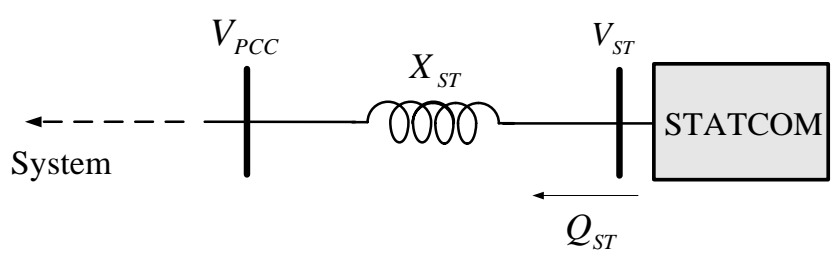

Fig. 1. STATCOM reactive power 
The terminal voltage of a load that needs a variable reactive power (like an arc furnace), will vary as well. Thus, if a STATCOM is connected near to this load with a constant ac side voltage, the reactive power supplied by the STATCOM will follow the reactive power required by the load. Equation (1) shows clearly how it works: if $V_{S T}$ is a constant and $V_{P C C}$ varies, the capacitive or inductive reactive power supplied by the STATCOM will change according to the $V_{P C C}$ variations.

Of course this is a simplified analysis that does not guarantee full reactive power compensation. Nevertheless, it gives a good insight on the proposed technique. Next sections will present two analysis of an example case: a simplified analytical treatment and a detailed analysis using EMTP/ATP simulations.

\section{THE STUDIED CASE: ANALYTICAL MODEL}

In order to study the STATCOM multi-pulse application to control reactive power oscillations, a simple circuit was analyzed (Figure 2). This circuit is composed by an ideal source in $230 \mathrm{kV}$, a $200 \mathrm{~km}$ transmission line and a wyedelta transformer (230-18 kV). On the $18 \mathrm{kV}$ bus, a 12-pulse STATCOM and an arc furnace are connected. The arc furnace is rated at $73 \mathrm{MVA}$ and its nominal voltage is $426 \mathrm{~V}$.

The equivalent circuit of the studied system is presented in Figure 3, where all components are represented in a simplified way. The STATCOM is represented by an ideal voltage source (without harmonics). The transmission line and the transformer are represented by a single inductive reactance $(X)$. The arc furnace is modeled by an inductive reactance ( $X_{L}$, representing the transformer and the reactance of the flexible cable of the furnace) in series with a variable resistance $(R$, representing the electric arc and the flexible cable resistance). The inductance of flexible cable provides a delay in the furnace current, returning a more stable arc [2]. Finally, the converter transformer is also represented by its reactance $\left(X_{S T}\right)$.

The circuit shown in Figure 3 can be analyzed through a Thévenin equivalent circuit that includes the ac source and the STATCOM, as seen from the arc furnace. This way, the Thévenin voltage and impedance are given by (2):

$$
\left\{\begin{array}{l}
V_{t h}=\frac{V_{S T} X+V_{S} X_{S T}}{X+X_{S T}} \\
Z_{t h}=j \frac{X_{S T} X}{X_{S T}+X}
\end{array},\right.
$$

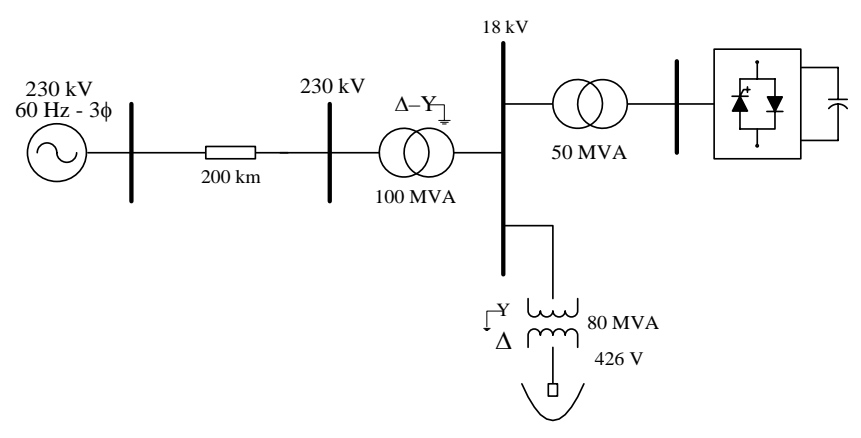

Fig. 2. Single-line diagram of studied system

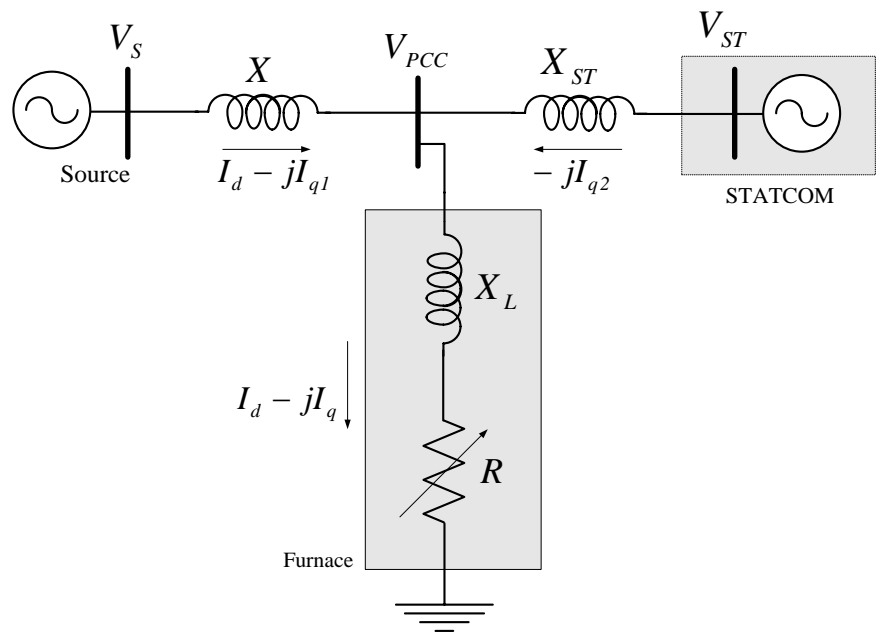

Fig. 3. Single-line diagram of analytical study

where:

$$
\begin{aligned}
& V_{t h}-\text { Thévenin equivalent voltage; } \\
& Z_{t h}-\text { Thévenin equivalent impedance. }
\end{aligned}
$$

In general, the STATCOM impedance $\left(X_{S T}\right)$ is larger than the system impedance $(X)$. However, if they were in the same order of magnitude, a reduction of $50 \%$ in the equivalent impedance at the point of common coupling is obtained. Naturally, the smaller the $X_{S T}$, the smaller will be the equivalent impedance $Z_{t h}$. It means that the STATCOM approximates the load to the rest of the ac system.

Figure 3 shows also the currents components in dq0 frames, which flow through the system. Here, $I_{d}$ is phase displaced by $90^{\circ}$ from $I_{q}$. Furthermore, the direct component $I_{d}$ represents the active part of total current, while the quadrature component $I_{q}$ indicates the reactive part of total current. The active power consumption nature of the arc furnace is represented by a variable resistor $R$. In fact, each phase has a different value of $R$. However, in this simplified analytical study, the arc furnace was considered a balanced load.

As the firing is done in order to produce zero angular difference between $V_{S T}$ and $V_{P C C}$, only reactive current will flow between the converter and the system. Moreover, the current $I_{d}$ demanded by the arc furnace must be supplied by the ac source through the transmission line. If the compensation is perfect, the load reactive current $I_{q}$ is totally compensated by the STATCOM current $I_{q 2}$. If compensation is partial, some reactive current $I_{q 1}$ will flow from the ac source.

Changing the arc resistance $R$, the reactive current demanded by the furnace $I_{q}$ and the reactive current effectively supplied by the converter $I_{q 2}$ can be calculated. The calculation methodology is described in the Appendix. All the system parameters can be found in Table I. The per unit values were calculated taking $100 \mathrm{MVA}$ and $18 \mathrm{kV}$ as the basis for power and voltage at PCC, respectively.

Figure 4 shows $I_{q}$ (furnace) and $I_{q 2}$ (STATCOM) currents as a function of the furnace resistance $R$. The STATCOM current always closely keeps up with the furnace current. However, an error exists, which depends on system parameters, furnace power and also on STATCOM voltage. An ade- 
TABLE I

Simplified System Parameters

\begin{tabular}{ll}
\hline Parameter & Value \\
\hline ac system equivalent reactance $(X)$ & $0.326 \mathrm{pu}$ \\
\hline equivalent reactance of STATCOM $\left(X_{S T}\right)$ & $0.400 \mathrm{pu}$ \\
\hline ac system voltage $\left(V_{S}\right)$ & $1.000 \mathrm{pu}$ \\
\hline arc furnace equivalent reactance $\left(X_{L}\right)$ & $0.318 \mathrm{pu}$ \\
\hline
\end{tabular}

quate converter voltage level can bring better results. For the case represented in Figure 4, the worst case occurs for the smallest resistance value, achieving an error of $10.5 \%$. At this point, the furnace would demand a reactive current equal to $0.468 \mathrm{pu}$ and the STATCOM will deliver 0.363 . The difference $(0.105 \mathrm{pu})$ would have to come from the source.

In the previous case, the STATCOM voltage was fixed in $1.05 \mathrm{pu}$. If, for instance, the STATCOM voltage is fixed in $1.10 \mathrm{pu}$, the reactive current profiles would be displaced, as shown in Figure 5. In this case, the maximum error is equal to $16.3 \%$. We can see that, for high reactive current values, the error is small. On the other hand, as the level of reactive power required by the load decrease, the compensation error increase. It means that that STATCOM is working well in the more critical situations.

The results show that the choice of the STATCOM voltage is essential for adequate system performance. However, the reactive current supplied by the converter will always keep up with the demanded furnace current.

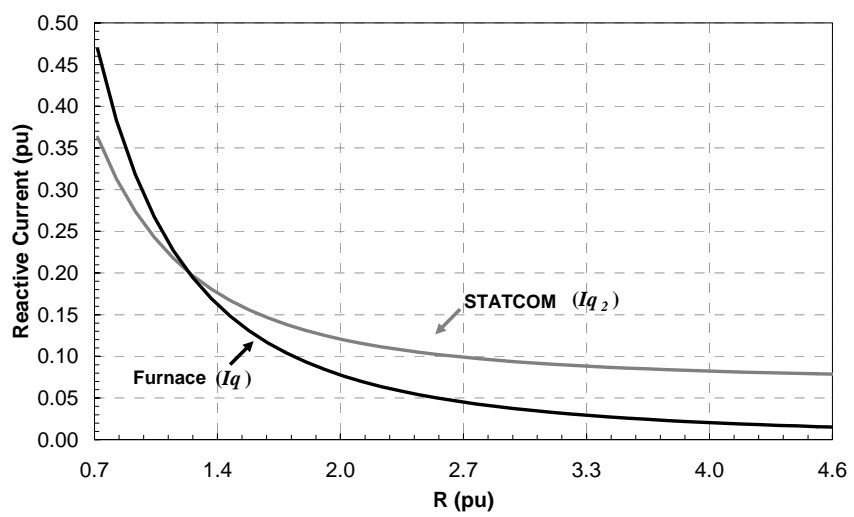

Fig. 4. Results obtained from the analytical study $-V_{S T}=1.05 \mathrm{pu}$

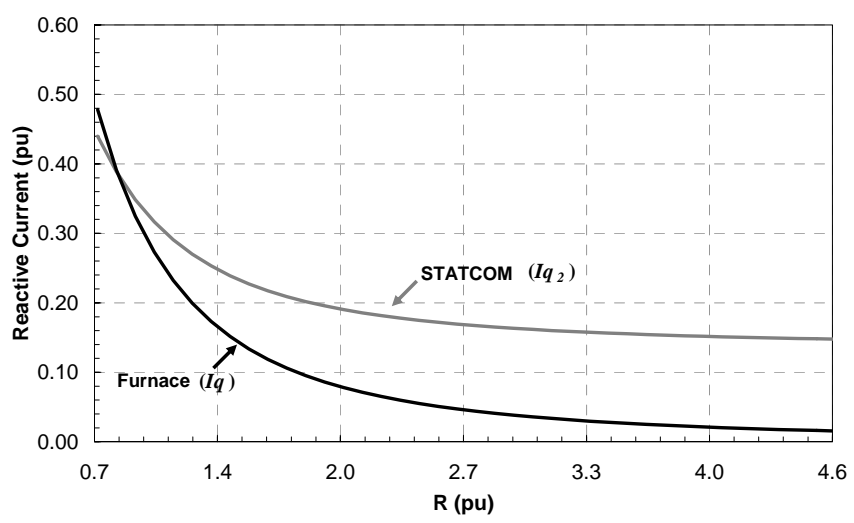

Fig. 5. Results obtained from the analytical study $-V_{S T}=1.10 \mathrm{pu}$

\section{THE STUDIED CASE: DIGITAL TRANSIENT MODEL}

The system shown in Figure 2 was implemented in a detailed way using EMTP/ATP program. Here, a brief description of each model as well as the STATCOM control system is described.

\section{A. The STATCOM Model}

The STATCOM model is described in detail in [3]. It is a 12-pulse converter and its main characteristics are presented in Table II. The converter valves are represented in detail, including the GTOs and diodes, and also the snubber circuits.

In order to analyze the proposed control methodology apart from the unbalance problem, the dc capacitor was replaced by an ideal dc voltage source.

\section{B. The Arc Furnace Model}

The arc furnace model was described and validated by Sollero et al. [2]. This model is based on [4] which suggests that the arc resistance changes, at each semi-cycle, following a normal distribution. So, this is a random process, which emulates the arc furnace behavior. The model was implemented using the EMTP/ATP program, as presented in [2].

This model allows for the calculation of the arc resistance values for each phase, representing the furnace as an unbalanced load.

\section{The Control System}

In order to guarantee that the STATCOM voltage is constant, the original control system, presented in [3], was modified. In the original control system, the control signal is the difference between the reactive current in the output of the converter and a reference current (in this case, the load reactive current). In an arc furnace, the reactive current presents very high variations, because of the arc instability. So, with this kind of control, the STATCOM does not lead to good results, because it can not respond to the high frequency variations in furnace reactive current.

To implement the methodology proposed here, the control signal is the instantaneous active power at the output of the converter. The controller operates to maintain a null average active power flow between the STATCOM and the ac system, except for the losses in the STATCOM. In this way, the dc capacitor voltage should stay constant, with negligible voltage ripple in actual cases. Then, the STATCOM ac voltage is constant. Besides, there is a PLL (Phase Locked Loop) circuit, which synchronizes the firing to the switches, and guarantees that no displacement angle appears between the STATCOM and the system voltages.

TABLE II STATCOM Parameters

\begin{tabular}{ll}
\hline Parameter & Value \\
\hline ac nominal voltage & $18 \mathrm{kV}$ \\
\hline fundamental frequency & $60 \mathrm{~Hz}$ \\
\hline total apparent power & $50 \mathrm{MVA}$ \\
\hline number of pulses & 12 \\
\hline dc rated voltage (without compensation) & $11.54 \mathrm{kV}$ \\
\hline
\end{tabular}


Figure 6 shows the complete control system. The first block receives the voltages and currents in the output of the converter and calculates the instantaneous active power. This value is compared with a null reference, producing an error signal, which is the input of a PI (proportional-integral) controller. Finally, the controller gives a displacement angle necessary to lead or lag the ac converter voltage and obtain the desired reference. Furthermore, the PLL circuit, which is composed by a phase comparator, a PI controller and a voltage controlled oscillator, is also shown.

This kind of controller would work well if the furnace were a balanced load. As a multi-pulse STATCOM can generate only balanced voltages (this is an inherent characteristic of the STATCOM being considered), it is not possible to obtain a total compensation. It is not possible to maintain always the three-phase voltages of the converter in phase with the three system voltages. In this case, an oscillatory active power flow will always be present between the STATCOM and the system. Depending on the unbalance level, this active power can achieve high levels and the dc capacitor has to be very large to keep the voltage constant (or close to constant). At the end of this paper a more precise discussion about the capacitor size is presented.

\section{The Transmission Line and Transformers}

The transmission line was modeled using distributed parameters that correspond to a typical $230 \mathrm{kV}$ line.

The power transformer $(230-18 \mathrm{kV})$, the STATCOM transformer and the furnace transformer were represented using only their leakage impedance.

\section{SIMULATION RESULTS}

Using the models described in the previous section, simulations were performed using the EMTP/ATP program. Initially, the STATCOM was removed from the system to show the reactive current characteristics. Then, the STATCOM with the proposed control technique was introduced, showing that reactive power oscillations are compensated. In all analysis, the simulation time step was equal to $10 \mu \mathrm{s}$.

\section{A. Case \#1: Without STATCOM}

Figure 7 shows the reactive current provided by the ac system $\left(i_{q 1}\right)$ when the STATCOM is not connected. It shows the instantaneous value and an average value computed along the simulation, in a cumulative mode. The cumulative average value was computed using (3):

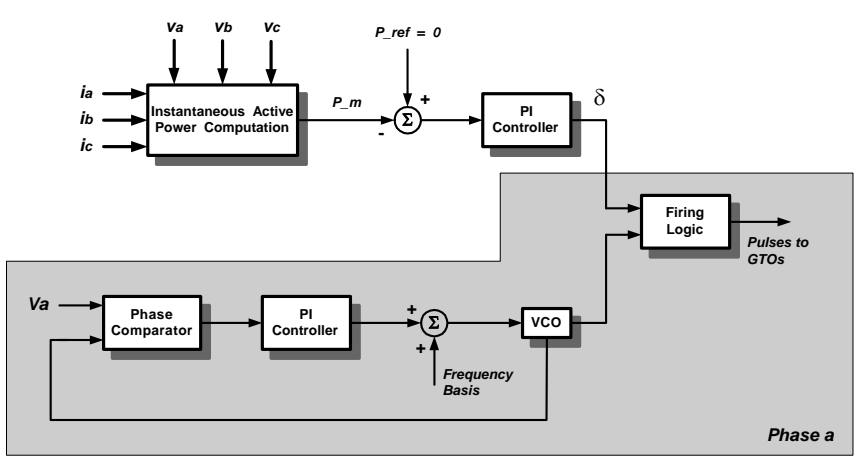

Fig. 6. The completed control system

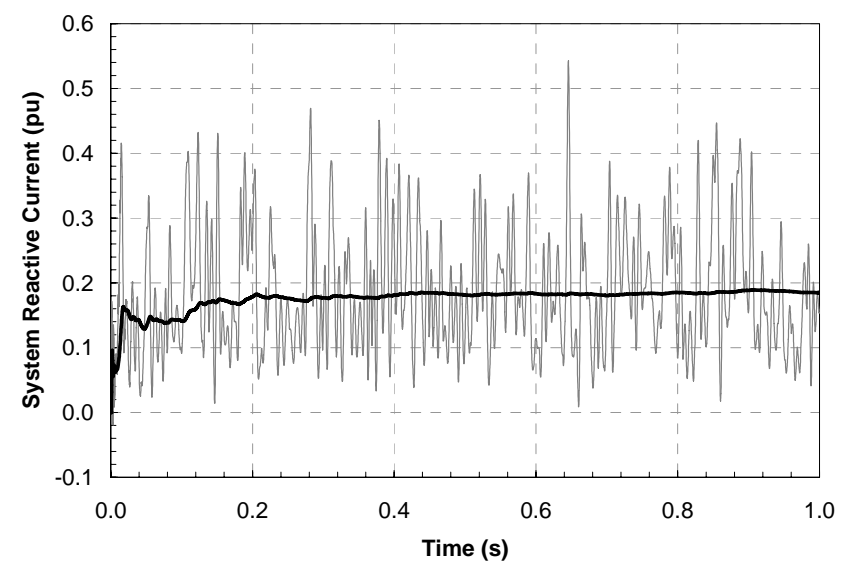

Fig. 7. System reactive current: without STATCOM

$$
\bar{i}_{q 1}(t)=\frac{1}{t} \int_{o}^{t} i_{q 1}(\tau) d \tau \quad(t>0),
$$

where ' $\tau$ ' is the integration variable (time).

Equation (3) gives the average of current $i_{q 1}$ from zero to time $t$. The use of conventional average or rms value was not considered here because the period of the oscillations was a completely random variable.

As the STATCOM is not connected, all the reactive current required by the load (the arc furnace) is supplied by the ac system. Because of the random arc characteristic, the reactive current oscillates very much. The average value is close to $0.2 \mathrm{pu}$.

\section{B. Case \#2: With STATCOM}

Figure 8 shows again the reactive current provided by the ac system, but now, in $t=1.0 \mathrm{~s}$, the STATCOM is connected.

In Figure 8, the cumulative average value is also shown. It is important to say that this average value was calculated for two distinct periods: from 0.0 to $1.0 \mathrm{~s}$ (without STATCOM) and from 1.0 to $2.0 \mathrm{~s}$ (with STATCOM). When the converter is connected, the average value stays close to zero

Figure 9 shows the STATCOM $\left(i_{q 2}\right)$ and the furnace $\left(i_{q}\right)$ reactive currents obtained in this simulation. As expected, the converter tracks the fast variations in the furnace reactive current. It is possible to see that some errors appear in a few

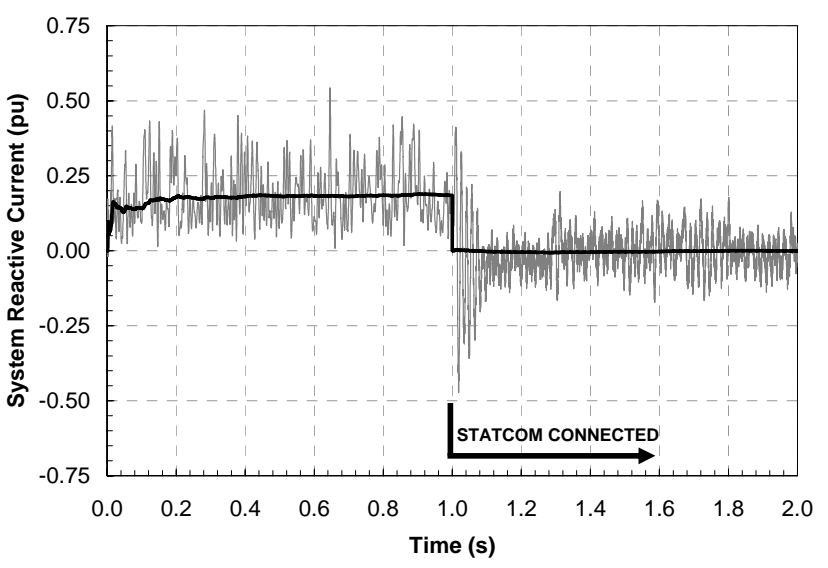

Figure 8. System reactive current 


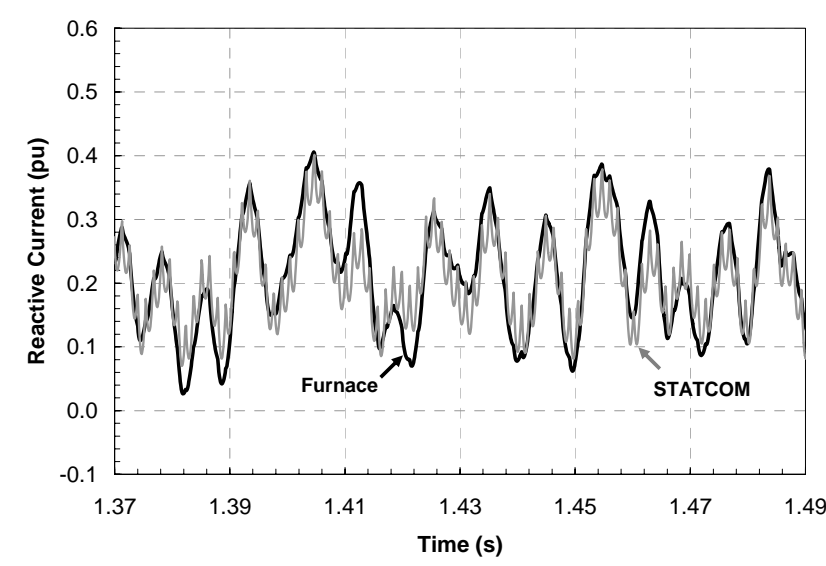

Fig. 9. STATCOM and arc furnace reactive currents

points. These errors are function of the switching, load unbalance and the chosen dc voltage value.

The authors presented [3] a detailed frequency response of this 12-pulse STATCOM, considering a direct control of reactive current. It was shown that, if the reactive current is used as the control signal, the converter can respond to frequencies up to $20 \mathrm{~Hz}$. When the reactive current is not directly controlled, and the control system acts in order to maintain the STATCOM voltage constant, automatic control of the reactive current is obtained, as shown in Figure 9. In the case of an arc furnace, the main reactive current oscillations appear at a frequency close to $100 \mathrm{~Hz}$. Using, the conventional control philosophy, these results could not be achieved. Therefore, the proposed technique provides an evolution in the range of frequencies controlled by the STATCOM.

Reactive currents presented in Figure 9 do not include any kind of filtering, so it is possible to see some harmonic components in the STATCOM current, due to the switching. If a 24-pulse or a 48-pulse configuration is used, this noise could be reduced.

In order to quantify the compensation level of the reactive power provided by the STATCOM, a "compensation index CI” can be defined as (4):

$$
C I \%=\left(1-\frac{\sum_{t=t_{i}}^{t=t_{f}}\left|i_{q_{-} L O A D}(t)-i_{q_{-} \text {STATCOM }}(t)\right|}{N}\right),
$$

where:

$$
\begin{aligned}
& t_{i} \text { - Initial time of the analyzed period; } \\
& t_{f}-\text { Final time of the analyzed period; } \\
& i_{q_{-} \text {LOAD }}(t) \text { - Reactive current of the load in time } t \text {; } \\
& i_{q_{-} S T A T C O M}(t)-\text { Reactive current of the converter in time } t \text {; } \\
& N=\left(t_{f}-t_{i}\right) / \Delta t, \Delta t \text { is the simulation time step. }
\end{aligned}
$$

Considering the simulation period shown in Figure 9, (4) provides a compensation index of 93\%. This result was obtained with a STATCOM ac side voltage $\left(V_{S T}\right)$ equal to $1.1 \mathrm{pu}$. This value is a consequence of the selected dc voltage value, which depends on the amount of reactive power to be compensated.

Another important result refers to the voltage at the point of common coupling $V_{P C C}$. Figure 10 shows its rms value, which was computed for each waveform cycle. The average rms value is also shown for both periods (with and without STATCOM). Because of the very random arc behavior, the rms voltage oscillates too much. However, it can be seen that, when the STATCOM is connected $(t=1.0 \mathrm{~s})$, these oscillations are reduced. Without STATCOM, the average value of the rms voltage is $10.2 \mathrm{kV}$ and the maximum ripple achieves 5.8\%. After converter connection, the average value of rms voltage increases to $10.8 \mathrm{kV}$ and the maximum ripple is $2.8 \%$.

Schauder [5] shows very interesting results about the application of STATCOMs for compensation of large electric arc furnace installations. However, the author does not give clear information about the topology and the control system employed.

\section{Capacitor Sizing}

The active power control response is presented in Figure 11. As expected, the average value is close to zero. However, there is an oscillatory active power, which achieves high values (about $0.17 \mathrm{pu}$ ). This fact shows that the STATCOM is compensating not only the reactive power, but also the oscillatory active power required by the arc furnace.

Active filters would be a better solution to compensate the oscillatory component of active power. In [6], Casaravilla et al. use a shunt active filter to reduce the harmonic distortion in an arc furnace installation. Often, hybrid configurations can be the choice to obtain a complete compensation.

If a capacitor is to be used in place of the ideal source, its size could be calculated according to the amount of energy in a semi-cycle (Area $A$ in Figure 11). The dc capacitor energy variation is given as a function of the active power in the ac side by (5):

$$
\Delta E=\frac{1}{2} C V_{1}^{2}-\frac{1}{2} C V_{2}^{2}=\int_{t_{1}}^{t_{2}} p(t) d t=A,
$$

where:

\section{A - Area shown in Figure 11 (a "typical” block of energy}

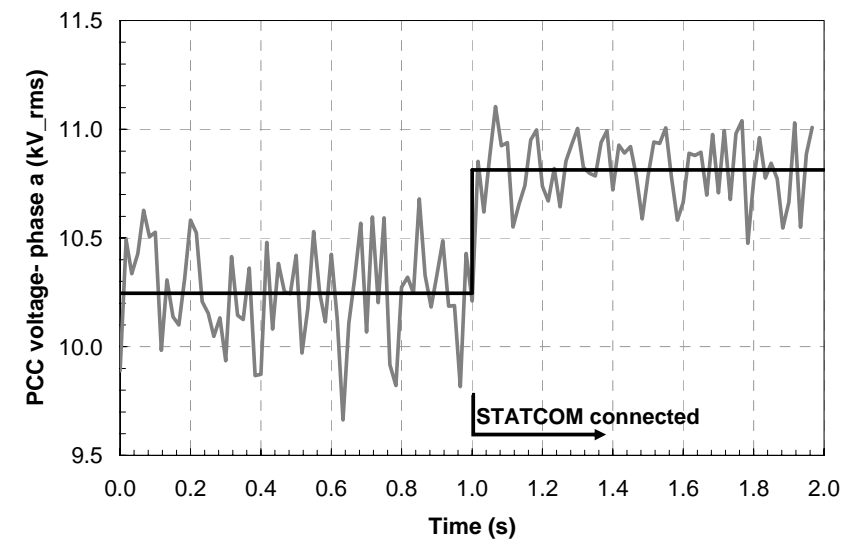

Fig. 10. Point of common coupling voltage, $V_{P C C}$ 
flowing into the dc capacitor);

$t_{1}$ and $t_{2}-$ Initial and final time, respectively, as indicated in Figure 11;

$V_{1}$ and $V_{2}$ - Capacitor voltage at $t_{1}$ and $t_{2}$, respectively; $p(t)$ - Instantaneous active power.

With (5) it is possible to determine the capacitor size. In this study, a capacitance of $26500 \mu \mathrm{F}(11.54 \mathrm{kV})$ would be necessary to guarantee a maximum dc voltage variation of $2 \%$. If $5 \%$ voltage ripple is allowed at the dc capacitor, a capacitor of $10600 \mu \mathrm{F}$ would be enough.

In [7], Akagi shows that a flywheel energy storage system, using a doubly-fed machine operating as a variable speed synchronous condenser, can be a good alternative when the system needs a device with the capability of repetitively releasing or absorbing active power in time period around $100 \mathrm{~ms}$.

\section{CONCLUSIONS}

The paper has showed that, maintaining constant the dc capacitor voltage of a STATCOM, it is possible to compensate fast oscillating reactive power. The technique is based on the simple fact that the reactive power supplied by the STATCOM is directly related to the difference between the STATCOM ac side voltage and the ac system voltage.

The proposed technique was tested using a simple circuit where a 12-pulse STATCOM and an arc furnace were connected. A simplified analytical study and a detailed analysis with EMTP/ATP simulations were performed.

The presented results have shown that by fixing the ac STATCOM voltage, an automatic compensation for the reactive current of some loads can be achieved. However, there is always an error associated with this compensation, which can be minimized through a correct choice of the dc capacitor voltage. Moreover, in the case of arc furnaces, which are deeply unbalanced loads, an oscillatory active power appears between the STATCOM and the ac system. The adequate compensation of this power is possible, but it requires a high capacitance value.

The method was tested in a 12-pulse STATCOM, but it should present better results when applied in a 24 or 48-pulse STATCOM or even in a PWM device. The contribution of this work is the proposal of maintain the STATCOM voltage

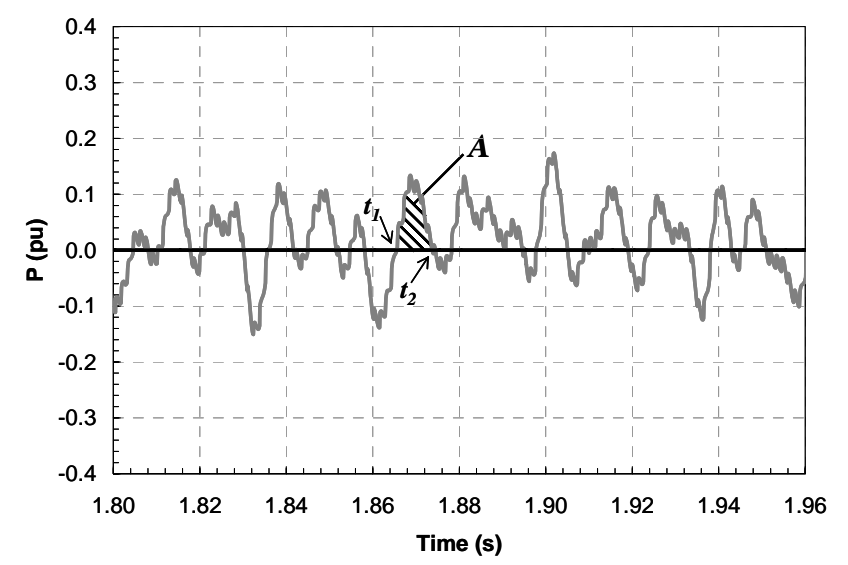

Fig. 11. Oscillatory active power constant, which improves its performance in compensating fast varying reactive power. The use of a conventional or a variable speed synchronous machine (doubly-fed machine), operating with constant voltage, can produce similar results.

\section{APPENDIX}

To compute the STATCOM and arc furnace reactive current, it was assumed that there is no angular difference between the furnace terminal voltage $\left(V_{P C C}\right)$ and the STATCOM ac side voltage $\left(V_{S T}\right)$. It means that no active power is supplied from or to the STATCOM. Moreover, the magnitudes of STATCOM ac side voltage $V_{S T}$ and the system voltage $V_{S}$ were considered constants.

In the following equations, complex quantities were distinguished from the real ones by using a “dot”.

\section{Currents in the equivalent system}

The current that flows from the STATCOM can be written as:

$$
\left\{\begin{array}{l}
\dot{I}_{S T}=\frac{\dot{V}_{S T}-\dot{V}_{P C C}}{j X_{S T}} \\
\dot{I}_{S T}=-j I_{q 2}
\end{array} .\right.
$$

The current that flows from the ac systems is:

$$
\dot{I}_{S}=\frac{\dot{V}_{S}-\dot{V}_{P C C}}{j X} .
$$

Finally, the furnace current is given as:

$$
\dot{I}_{F}=\frac{\dot{V}_{P C C}}{R+j X_{L}} .
$$

\section{Kirchhoff's current law}

By the Kirchhoff's current law:

$$
\left\{\begin{array}{l}
\dot{I}_{F}=\dot{I}_{S}+\dot{I}_{S T} \\
\frac{\dot{V}_{P C C}}{R+j X_{L}}=\frac{\dot{V}_{S}-\dot{V}_{P C C}}{j X}+\frac{\dot{V}_{S T}-\dot{V}_{P C C}}{j X_{S T}}
\end{array} .\right.
$$

Using the STATCOM voltage (and consequently the furnace voltage) as angular reference, we can write:

$$
\left\{\begin{array}{l}
\dot{V}_{S}=V_{S} \angle 0^{\circ}=V_{S} \\
\dot{V}_{P C C}=V_{P C C} \angle 0^{\circ}=V_{P C C}
\end{array}\right.
$$

Rewriting (iv) using (v):

$$
\begin{aligned}
& \dot{V}_{S}=\frac{-V_{P C C}\left(X_{S T} X+X_{S T} X_{L}+X_{L} X\right)}{j R X_{S T}-X_{S T} X_{L}}+ \\
& +\frac{V_{S T} X_{L} X+j\left(R V_{P C C} X_{S T}-R V_{S T} X+R V_{P C C} X\right)}{j R X_{S T}-X_{S T} X_{L}}
\end{aligned}
$$

Computing the magnitude of $V_{S}$ and simplifying the result: 


$$
\begin{gathered}
V_{S}=\sqrt{A+B} \\
A=\frac{R^{2}\left[V_{S T} X-V_{P C C}\left(X+X_{S T}\right)\right]^{2}}{\left(R^{2}+X_{L}^{2}\right) X_{S t}^{2}} \\
B=\frac{\left[V_{S T} X_{L} X-V_{P C C}\left(X_{S T} X+X_{S T} X_{L}+X_{L} X\right)^{2}\right]}{\left(R^{2}+X_{L}^{2}\right) X_{S T}^{2}}
\end{gathered}
$$

In the above expression, all terms are constants, except the resistance $R$ and the furnace bus voltage $V_{P C C}$. This way, for each value of $R$, it is possible to calculate the corresponding value of $V_{P C C}$.

Then, the STATCOM reactive current $I_{q 2}$ and the furnace reactive current $I_{q}$ are given as:

$$
\left\{\begin{array}{l}
\dot{I}_{S T}=\frac{V_{S T}-V_{P C C}}{j X_{S T}}=-j \frac{V_{S T}-V_{P C C}}{X_{S T}}, \\
\Rightarrow I_{q 2}=\frac{V_{S T}-V_{P C C}}{X_{S T}}, \\
\dot{I}_{F}=\frac{V_{P C C}}{R+j X_{L}}=\frac{V_{P C C} R}{R^{2}+X_{L}^{2}}-j \frac{V_{P C C} X_{L}}{R^{2}+X_{L}^{2}}, \\
\Rightarrow I_{q}=\frac{V_{P C C} X_{L}}{R^{2}+X_{L}^{2}}
\end{array}\right.
$$

\section{ACKNOWLEDGEMENT}

This work was partially supported by PRONEX/CNPq.

\section{REFERENCES}

[1] N. G. Hingorani and L. Gyugyi, Understanding FATCS: concepts and technology of flexible ac transmission systems, IEEE Press, New York, 1999.

[2] R. B. Sollero et al., "Arc Furnace Modelling for Estimation of Voltage Fluctuation”, in Proc. of $X V$ National Seminar on Electric Energy Production and Transmission - SNPTEE, Iguassu Falls, October, 1999 (in Portuguese).

[3] T. M. L. Assis, E. H. Watanabe and L. A. S. Pilotto, "Analisys of Steady-State and Dynaminc Performance of a Static Synchronous Compensator (STATCOM)”, in Proc. of International Conference on Power System Transients, IPST'01, Rio de Janeiro, Brazil, pp. 505510, June 24-28, 2001.

[4] H. M. Petersen, R. G. Koch, P. H. Swart and R. Van Heerden, "Modelling Arc Furnace Flicker and Investigating Compensation Techniques", in Proc. of IEEE Thirtieth IAS Annual Meeting, IAS '95, vol. 02, pp. 1733-1740, October, 1995.

[5] C. Schauder, "STATCOM for Compensation of Large Electric Arc Furnace Installations,” in Proc. of IEEE Power Engineering Society Summer Meeting, vol. 02, pp. 1109-1112, 18-22 July, 1999.
[6] G. Casaravilla, A. Salvia, C. Briozzo and E. H. Watanabe, "Control Strategies of Selective Harmonic Current Shunt Filter", IEE Proc.-Gener. Transm. Distrib., vol. 149, no. 2, pp. 689-694, December, 2002.

[7] H. Akagi, "Large Static Converters for Industry and Utility Applications”, Proceedings of the IEEE, vol. 89, pp. 976-983, no. 6, June, 2001.

\section{BIOGRAPHIES}

Tatiana Mariano Lessa de Assis was born in Rio de Janeiro State, Brazil, on May 26, 1975 . She received the B.Sc. degree from Fluminense Federal University, Rio de Janeiro State, in 1999 and the M.Sc. degree in Electrical Engineering from Federal University of Rio de Janeiro in 2000. Her main fields of interests are power systems analysis, FACTS applications and power quality.

During 04 years, she worked at CEPEL (The Brazilian Electric Power Research Center), in power quality analysis. Between 2001 and 2003, she worked at ONS (The Brazilian ISO) in power systems analysis. Nowadays, she is a D.Sc. student at COPPE/Federal University of Rio de Janeiro and works with the power systems studies group.

Ms. Assis is a student member of IEEE.

Edson Hirokazu Watanabe was born in Rio de Janeiro State, Brazil, on November 07, 1952. He received the B.Sc. in Electronic Engineering and M.Sc. in Electrical Engineering in 1975 and 1976, respectively, from the Federal University of Rio de Janeiro. In 1981 he got the D.Eng. degree from Tokyo Institute of Technology, Japan. His main fields of interests are converters analysis, modeling and design, active filters and FACTS technologies.

In 1981 he became an Associate Professor and in 1993 a Professor at COPPE/Federal University of Rio de Janeiro, where he teaches Power Electronics.

Dr. Watanabe is a member of the IAS, PES and PELS Societies of IEEE, the IEE-Japan, The Brazilian Society for Automatic Control, The Brazilian Power Electronics Society and CIGRE-Brazil.

Luiz Alberto da Silva Pilotto was born in Rio de Janeiro, Brazil, on June 20, 1959. He received the B.Sc., M.Sc. and D.Sc. degrees in electrical engineering, in 1981, 1983 and 1994, respectively, from the Federal University of Rio de Janeiro. He research interests are in the analysis of HVdc transmission systems, FACTS devices, Power Electronic controllers, SCADA/EMS systems and Energy Market Structures.

Since 1983 he has been working at CEPEL, the Brazilian Electrical Energy Research Center. During three years he was a Program Manager responsible for Supervision, Control and Protection of Power Systems. He is currently R\&D Director. During 1984 he expended 6 months at ABB Switzerland working with the application of static phase-shifters to damp out SSR oscillations and state space modeling of ac/dc systems. He was invited again by the same company in 1988 and developed EMTP HVdc control models to simulate the Pacific Intertie Expansion system. On the last twelve years, he has been involved in the analysis of control interactions 
among multiple HVdc converter station and FACTS devices operating at the same electrical area.

Dr. Pilotto became a Member of the Institute of Electrical and Electronics Engineers (IEEE) in 1987. He is currently a Senior Member of the IEEE Power Engineering, Control Systems and Power Electronics Societies. He also participates in Cigré SC-14, 38 \& 39. Dr. Pilotto is Past Secretary, Treasurer, Vice-Chairman and Chairman of IEEE Rio de Janeiro Section. He is currently Chairman of the IEEE PES Rio de Janeiro Chapter.

Raul Balbi Sollero received the B.Sc. in Electrical Engineering from the Federal University of Minas Gerais, Brazil and the M.Sc. degree in Electrical Engineering from the Federal University of Rio de Janeiro - COPPE.

He joined CEPEL - Electric Power Research Center in 1982, where, since 2000, he is the manager of the area of Supervision, Control and Protection of Power Systems. His main fields of interest include power system protection and stability, signal processing and equipment modeling for transient studies.

Mr. Sollero is a member of IEEE and integrates the Technical Committee of the International Conference on Digital Power System Simulators. 